Estudios Constitucionales, Año 13, № 2, 2015, pp. 421-446

ISSN 07180195

Centro de Estudios Constitucionales de Chile Universidad de Talca

"Un 'putsch judicial': comentarios explicativos de sentencia de la Corte Suprema

de Estados Unidos declarando la inconstitucionalidad de las leyes de cuatro estados que regulaban el matrimonio como unión solo entre un hombre y una mujer"

Allan R. Brewer-Carías

\title{
UN "PUTSCH JUDICIAL": COMENTARIOS EXPLICATIVOS DE SENTENCIA DE LA CORTE SUPREMA DE ESTADOS UNIDOS DECLARANDO LA INCONSTITUCIONALIDAD DE LAS LEYES DE CUATRO ESTADOS QUE REGULABAN EL MATRIMONIO COMO UNIÓN SOLO ENTRE UN HOMBRE Y UNA MUJER*
}

\author{
AlLan R. BReWer-Carías ${ }^{1}$ \\ Universidad Central de Venezuela \\ abrewer@bblegal.com
}

\section{LA SENTENCIA, LA NOCIÓN DEL MATRIMONIO \\ Y LAS CARENCIAS CONSTITUCIONALES}

El título del presente comentario (putsch judicial) no es mío. Fue el que utilizó el juez Scalia, en su voto disidente, para calificar la sentencia dictada por la Corte Suprema de los Estados Unidos, el 26 de junio de 2015, dictada en writ of certiorari en los casos James Obergefell, et al., Petitioners 14-556 V. Richard Hodges, Director, Ohio Department Of Health, et al.; Valeria Tanco, et al., Petitioners 14-562 V. Bill Haslam, Governor of Tennessee, et al.; April Deboer, et al., Petitioners 14-571 V. Rick Snyder, Governor of Michigan, et al.; And Gregory Bourke, et al., Petitioners 14-574 V. Steve Beshear, Governor of Kentucky, (conocida como J. Obergefell v. Hudges) (US $575(2015)^{2}$.

\footnotetext{
* Trabajo recibido el 6 de julio de 2015 y aprobado el 12 de agosto de 2015.

1 Abogado y Doctor en Derecho por la Universidad Central de Venezuela (1962-1964). Desde 1963 es Profesor de la misma casa de estudios, donde fue Director del Instituto de Derecho Público. Ha sido Profesor Visitante (1972-1974) y Profesor de Posgrado (1985-1986) en la Universidad de Cambridge, Inglaterra; en la Universidad de Paris II (1990), y en las Universidades del Rosario y Externado de Colombia en Bogotá. Ha sido Profesor Visitante (2002-2004) y actualmente es Profesor Adjunto en la Universidad de Columbia de Nueva York.

2 Véase el texto en http://www.supremecourt.gov/opinions/14pdf/14-556_3204.pdf. El editorial del The New York Times consideró que con el calificativo el juez Scalia se había burlado ("mocked”) de la sentencia. Véase The New York Times, New York, June 27, 2015, p. A20.
} 
En dicha sentencia, partiendo del supuesto de que "no existe una unión tan profunda como el matrimonio", la Corte revocó las sentencias que se habían dictado por la United States Court of Appeals for the Sixth Circuit, en aplicación de las leyes de los estados de Ohio, Tennessee, Michigan y Kentucky que solo regulaban la posibilidad del matrimonio cuando era entre un hombre y una mujer.

Para dictar su decisión, la Corte Suprema consideró que la Constitución de 1787 "no permite que los Estados prohíban a las parejas del mismo sexo contraer matrimonio en los mismos términos y condiciones acordadas a las parejas de sexos contrarios", acogiendo así la petición de los peticionarios que eran catorce parejas del mismo sexo y dos hombres cuyas parejas habían fallecido, desechando la argumentación de los funcionarios demandados (todos encargados de ejecutar las leyes impugnadas de inconstitucionalidad) y considerando que los mismos habían "violado la Enmienda Catorce de la Constitución, al negarle a quienes reclamaban 'dignidad igual a los ojos de la ley', 'su derecho a casarse o a que sus matrimonios fueran legales en otros Estados, que le daban reconocimiento total'; todo partiendo de la base de que la 'dignidad igual a los ojos de la ley" era un derecho que les otorgaba la Constitución.

El juez Scalia, como se ha dicho, calificó la sentencia en su voto disidente, como "un golpe de estado judicial" (judicial putsch), pues con ella, cinco jueces que formaron la mayoría de la Corte, en definitiva concluyeron que:

"[...] cada Estado violó la Constitución durante todos los 135 años entre la ratificación de la Enmienda Catorce y la permisión en Massachusetts del matrimonio del mismo sexo en 2003. Ellos han descubierto en la Enmienda Catorce un 'derecho fundamental' ignorado por cada persona viva al tiempo de la ratificación, y por casi todo el mundo desde entonces. Ellos ven lo que menos importantes mentes jurídicas -mentes como Thomas Cooley, John Marshall Harlan, Oliver Wendell Holmes Jr., Learned Hand, Louis Brandeis, William Howard Taft, Benjamin Cardozo, Hugo Black, Felix Frankfurter, Robert Jackson y Henry Friendly- no pudieron ver. Ellos están seguros que el pueblo ratificó la Enmienda Catorce para otorgarles a ellos el poder de eliminar temas del proceso democrático cuando ello deriva de su 'razonado juicio'. Estos jueces saben que limitar el matrimonio a un hombre y una mujer es contrario a la razón; ellos saben que una institución tan vieja como el gobierno mismo, y aceptada por todas las Naciones en la historia hasta hace quince años, no puede ser apoyada por otra cosa que no sea la ignorancia o el prejuicio. Y están dispuestos a decir que cualquier ciudadano que no esté de acuerdo con ello, que se refiera a lo que fue hasta hace quince años el juicio unánime de todas las generaciones y todas las sociedades, es contrario a la Constitución". 
Como lo reafirmó el Chief Justice Roberts, también en su voto disidente, al cual se unieron los jueces Scalia y Thomas: "[...] como la mayoría lo reconoce, el matrimonio 'ha existido por milenios y a través de las civilizaciones', y siempre se ha referido 'a una sola relación: la unión entre un hombre y una mujer', lo que consideró que no es una 'coincidencia histórica', en el sentido de que

El matrimonio no surgió como consecuencia de un movimiento político, de un descubrimiento, de una enfermedad, de una guerra, de una doctrina religiosa, o de cualquier otra fuerza de la historia mundial $-\mathrm{y}$ ciertamente no como resultado de una decisión prehistórica de excluir a los homosexuales y lesbianas. Surgió de la naturaleza de las cosas para satisfacer la necesidad vital de asegurar que los hijos fueran concebidos por una madre y un padre comprometidos a levantarlos en condiciones estables durante la vida de su relación".

Por su parte, en cuanto al concepto de matrimonio, el juez Alito, en su voto disidente destacó sobre la concepción del matrimonio utilizada en la sentencia, que en la misma se sostiene que "el propósito fundamental del matrimonio es el promover el bienestar de los que se casan"; el de "dar satisfacción emocional y promesas de apoyo en tiempos de necesidad" y que "beneficiando a las personas que escogen casarse, el matrimonio beneficia indirectamente a la sociedad porque las personas que viven una vida en relación estable, satisfactoria y de soporte hace mejores ciudadanos". Es por estas razones, según expresó el mismo juez Alito, que el argumento de la Corte fue que:

“[...] los Estados promueven y formalizan el matrimonio, confieren especiales beneficios a las personas casadas, y también les imponen obligaciones especiales. Este entendimiento de las razones de los Estados para reconocer el matrimonio es lo que permite a la mayoría argumentar que el matrimonio del mismo sexo sirve a los objetivos de los Estados en la misma forma que los matrimonios de sexos opuestos. Este entendimiento del matrimonio, que se enfoca casi enteramente en la felicidad de las personas que escogen casarse, es hoy compartida por muchas personas, pero no es la tradicional. Por milenios, el matrimonio fue indisolublemente unido a una sola cosa que solo las parejas de sexo opuesto pueden hacer: procrear".

Ahora bien, la Constitución de Estados Unidos de 1787, como sucede con todas las antiguas muy antiguas o que contienen declaraciones muy escuetas de derechos fundamentales, nada dispuso en materia de matrimonio, ni como derecho de las personas ni como institución social protegida por el Estado; y ello, a pesar de que como lo observó Alexis de Tocqueville cuando visitó Norteamérica en 1835, "no hay país en el mundo donde el lazo del matrimonio sea tan respe- 
tado como en América" (Democracy in America 309 (H. Reeve transl., rev. ed. 1990, citado en la sentencia). La palabra "marriage", incluso, no es utilizada en ninguna de sus normas.

Esto, al contrario de lo que sucede en constituciones más modernas, como por ejemplo la de Venezuela, cuyo artículo 77 dispone en los términos antes mencionados que destacaron el Chief Justice Roberts y el juez Alito en sus votos disidentes, que "se protege el matrimonio entre un hombre y una mujer, fundado en el libre consentimiento y en la igualdad absoluta de los derechos y deberes de los cónyuges", agregándose que "las uniones estables de hecho entre un hombre y una mujer que cumplan los requisitos establecidos en la ley producirán los mismos efectos que el matrimonio". Sobre esta norma debo recordar que el proyecto de Constitución que se sometió a la consideración de la Asamblea Nacional Constituyente en la sesión del 26 de octubre de 1999, cuando tuvo lugar la primera discusión del texto constitucional, no contenía referencia alguna a que el matrimonio es una relación entre un "hombre y una mujer", habiendo sido aprobada la norma sin dicha precisión. Como consideré y considero que el matrimonio es una institución que solo puede ocurrir entre un hombre y una mujer (otras relaciones entre personas de un mismo sexo pueden ser reconocidas y protegidas, pero no por ello se tienen que llamar "matrimonio"), al finalizar la referida sesión de la Asamblea, consigné mi voto salvado con el siguiente texto:

"Salvo mi voto por considerar que no debió eliminarse, al protegerse el matrimonio, la referencia al 'hombre y la mujer' que traía la redacción original pues ya no parece ser obvio, en el mundo moderno, que los matrimonios solo deban existir entre hombre y mujer"3.

En la segunda discusión del proyecto se adoptó el texto finalmente sancionado, pudiendo decirse entonces que el tema del matrimonio como institución protegida por el Estado que solo puede ocurrir entre un hombre y una mujer, está expresamente regulado en la Constitución, por lo que no hay forma de interpretar sus previsiones en cuanto al matrimonio que no sea como una unión entre hombre y mujer, no pudiendo abarcar uniones de personas del mismo sexo.

En la Constitución de Estados Unidos, en contraste, como lo expresó el Chief Justice Roberts, en Voto disidente:

3 Véase en Brewer-Carías, Allan R., Asamblea Constituyente y Proceso Constituyente (1999), Tratado de Derecho Constitucional, Tomo VI, Editorial Jurídica Venezolana, Caracas, 2013, pp. 680-681. 
"[...] nada dice en sí misma sobre el matrimonio, y los Redactores en consecuencia asignaron a los Estados 'todo el tema de las relaciones domésticas entre esposo y esposa' Windsor, 570 U.S., at (slip op., at 17) (quoting In re Burrus, 136 U.S. 586, 593-594 (1890)). No hay discusión sobre el hecho de que cada Estado en su fundación -y todos los Estados a través de nuestra historia hasta hace una docena de años- definió el matrimonio en la forma tradicional, biológicamente fundada. Los cuatro Estados en estos casos son típicos. Sus leyes, antes y después han considerado el matrimonio como la unión entre un hombre y una mujer".

Y el hecho de que la Constitución nada regule en materia de matrimonio, significa que conforme al sistema federal de Estados Unidos, el régimen del mismo corresponde ser establecido exclusivamente por los estados. Por eso son las leyes de los Estados las que siempre han regulado el matrimonio.

Ahora bien, en cuanto a la Enmienda IV que se ha considerado violada por las leyes de los Estados que han establecido el matrimonio entre hombre y mujer, en la misma, en su parágrafo primero, lo que se indica es que:

“[...] Ningún Estado podrá hacer o imponer cualquier ley que pueda reducir los privilegios e inmunidades de los ciudadanos de los Estados Unidos; ni Estado alguno podrá privar a cualquier persona de su vida, libertad o propiedad, sin un debido proceso legal; ni negar a cualquier persona dentro de su jurisdicción protección igual de las leyes"4.

Esta es la norma constitucional que la Corte Suprema, en su sentencia, consideró violada al negarse a los peticionarios el derecho a casarse, para lo cual la Corte limitó su decisión a dos cuestiones: primero, presentada en los casos de Michigan y Kentucky sobre si la Enmienda Catorce requiere a que el Estado celebre matrimonio entre dos personas del mismo sexo, y segundo, presentada en los casos de los estados de Ohio, Tennessee y de nuevo Kentucky, si la Enmienda Catorce requiere que el estado reconozca el matrimonio del mismo sexo celebrado y realizado en un estado que sí otorgue ese derecho.

La sentencia fue dictada con el respaldo de cinco votos, bajo la opinión del juez Kennedy, a la cual se sumaron los jueces Ginsburg, Breyer, Sotomayor y Kagan, y los siguientes votos disidentes: el del Chief Justice Roberts, al cual se

4 Fourtheenth Amendment, 1 (1868): "No State shall make or enforce any law which shall abridge the privileges or immunities of citizens of the United States; nor shall any State deprive any person of life, liberty, or property, without due process of law; nor deny to any person within its jurisdiction the equal protection of the laws". 
sumaron los jueces Scalia y Thomas; el del juez Scalia, al cual se sumó el juez Thomas; el del juez Thomas, al cual se sumó el juez Scalia, y el del juez Alito, al cual se sumaron los jueces Scalia y Thomas.

Estas notas están destinadas a explicar las razones de la Corte Suprema al dictar su decisión, considerando la sentencia en particular desde el punto de vista del poder de la misma para controlar la constitucionalidad de las leyes (judicial review), sin entrar realmente en la discusión sobre el fondo decidido. Y ello, primero, en el mismo sentido que lo expresó el juez Scalia en su voto disidente, la sustancia de la sentencia en materia de matrimonio no es hoy lo importante, pues las leyes de los Estados pueden regular el tema como lo estimen las legislaturas, reconociendo el matrimonio cualquier vínculo sexual, lo cual puede tener efectos sociales adversos como otras leyes controversiales. Lo importante en realidad es saber quién es el que rige al ciudadano. Como lo expresó el juez Scalia:

"La decisión de hoy dice que mi Gobernante, y el Gobernante de 320 millones de americanos de costa a costa es una mayoría de los nueve jueces de la Corte Suprema. La decisión es estos casos, es la última extensión de hecho -y la última extensión que uno pueda imaginar- del poder que la Corte reclama para crear 'libertades' que ni la Constitución ni sus Enmiendas siquiera mencionan. Esta práctica de control de constitucionalidad por un comité no electo de nueve, siempre acompañada (como es hoy) de extravagantes admiraciones de libertad, le roba al Pueblo la libertad más importante que está en la Declaración de Independencia y venció en la Revolución de 1776: la libertad de gobernarse a sí mismo".

Igualmente, nuestros comentarios van en el sentido que expresó el juez Alito en su también voto disidente, en el sentido de que:

"La decisión de hoy tendrá un efecto fundamental en esta Corte y en su habilidad de sostener el Estado de derecho. Si una simple mayoría de jueces puede inventar un nuevo derecho e imponer ese derecho en el resto del país, el único límite real a lo que futuras mayorías podrán hacer, es su solo sentido sobre lo que esos con poder político e influencia cultural estarán dispuestos a tolerar. Incluso los entusiastas soportes del matrimonio del mismo sexo se preocuparán sobre el ámbito del poder que la mayoría de hoy reclama. La decisión de hoy muestra que décadas de intentos de restricción de los abusos de la autoridad de esta Corte han fracasado. Una lección que alguien va a sacar de la decisión de hoy es que predicar sobre el método apropiado de interpretación de la Constitución o de las virtudes del autocontrol y humildad judicial no pueden competir con la tentación de lograr lo que es visto por todos los medios prácticos como un final noble. Yo no tengo dudas que mis colegas en la mayoría ven sinceramente en la Constitución una visión de libertad que coincide con las de ellos 
mismos. Pero esta sinceridad es motivo de preocupación y no de seguridad. Lo que es evidente es lo hondo y quizá irremediable corrupción de nuestra concepción de cultura jurídica sobre interpretación constitucional".

Por ello el juez Alito expresó que aparte de que la decisión adoptada iba a ser celebrada y lamentada conforme a la propia visión sobre matrimonio del mismo sexo que tuvieran los americanos, "de lo que tendrían que preocuparse es de lo pretende el clamor de poder de la mayoría".

La sentencia se fundamentó básicamente en la noción de "libertad" que se establece en la Enmienda Catorce de la Constitución, la cual conforme se expresó en la primera frase de la sentencia, "incluye ciertos derechos específicos que permiten a las personas, dentro del reino de la legalidad, definir y expresar su identidad", partiendo de la base de que los peticionarios en estos casos buscaban "encontrar esa libertad al casarse con alguien de su mismo sexo y tener un matrimonio considerado como legal en los mismos términos y condiciones como el matrimonio entre personas de sexo opuesto".

\section{LA DISCUSIÓN SOBRE EL TEMA DEL MATRIMONIO DE PAREJAS DEL MISMO SEXO}

Después de constatar cómo desde finales del siglo XX hubo desarrollos culturales y políticos sustanciales que condujeron a personas del mismo sexo a llevar una vida más abierta y pública y a establecer familia, y destacar las discusiones que se originaron sobre ello tanto en el sector público como privado, con un cambio de actitud más tolerante en la materia, el tema de los derechos de los homosexuales y lesbianas llegó a las cortes de justicia, habiendo la Corte Suprema decidido muchos casos de importancia (Bowers v. Hardwick, 478 U.S. 186 (1986); Romer v. Evans, 517 U.S. 620 (1996); Lawrence v. Texas, 539 U.S. 558, 575; Baehr v. Lewin, 74 Haw. 530, 852 P. 2d 44).

Aun cuando ninguna de esas decisiones ordenó que fuera permitido el matrimonio entre personas del mismo sexo, algunos estados tuvieron preocupación sobre sus implicancias, y reafirmaron en sus propias leyes que el matrimonio se define como la unión entre parejas de sexo opuesto; e incluso en 1996 se dictó una ley federal Defense of Marriage Act (DOMA), 110 Stat. 2419, que definió al matrimonio a los efectos de todas las leyes federales "solo como la unión entre un hombre y una mujer como esposo y esposa”, 1 U.S.C. \$7. Otras discusiones siguieron, y en el estado de Massachusettes, su Corte Suprema en 2003 sostuvo que la Constitución del Estado garantizaba el derecho de las parejas del mismo sexo de casarse (Goodridge v. Department of Public Health, 440 Mass. 309, 798 N.E. 2d 941 (2003). Otros estados, igualmente, mediante legislación o decisiones 
judiciales reconocieron el mismo derecho, y la Corte Suprema, en United States v. Windsor, 570 U.S. (2013), otorgó derechos matrimoniales a parejas del mismo sexo, invalidando la Defense of Marriage Act (DOMA).

Además, con excepción de las sentencias sometidas a revisión en la sentencia, numerosas sentencias de las Cortes de Apelaciones, de las Cortes de Distrito y de las Cortes Supremas de los Estados en los últimos años han sostenido que excluir a parejas del mismo sexo de matrimonio viola la Constitución, y que debería permitirse que las mismas se casaran. En todo los Estados de la Unión en la materia al dictarse la sentencia estaban divididos.

\section{La EnMienda Catorce, la Libertad Y LA IDENTIFICACIÓN DE LOS “DERECHOS FUNDAMENTALES”}

Para decidir, la Corte Suprema se refirió a la llamada Due Process Clause de la Enmienda Catorce, que establece que ningún Estado podrá "privar a cualquier persona de su vida, libertad o propiedad, sin un debido proceso legal", estando incluidas dentro de las libertades fundamentales los derechos enumerados en el Bill of Rights (Duncan v. Louisiana, 391 U.S. 145, 147-149 (1968) y, además, las elecciones personales centrales a la dignidad individual y autonomía, incluso las escogencias íntimas que definen la identidad personal y las creencias (por ejemplo, Eisenstadt v. Baird, 405 U.S. 438, 453 (1972); Griswold v. Connecticut, 381 U.S. 479, 484-486 (1965).

De esa enumeración escueta de las libertades esenciales de las personas garantizadas en la Constitución, en una enumeración (vida, libertad y propiedad) que provienen de los trabajos de John Locke del siglo XVII, la Corte Suprema ha venido estableciendo lo que ha definido como los "derechos fundamentales", cuya "enumeración y protección", conforme se expresa en la sentencia que comentamos, "es una parte permanente del deber judicial de interpretar la Constitución” reconociendo, sin embargo, que "esa responsabilidad no ha sido reducida a fórmula alguna” (Poe v. Ullman, 367 U.S. 497, 542 (1961) (Harlan, J., dissenting).

Al contrario, sigue la sentencia, requiere de los tribunales "decisiones razonadas para identificar intereses de las personas que son tan fundamentales que el Estado les otorga protección", proceso que "guía muchas de las otras consideraciones relevantes en el análisis de otras previsiones constitucionales que establecen principios extensivos en lugar de requerimientos específicos”. Según la Corte,

“[...] ese método respeta nuestra historia y aprende de ella sin permitir que el pasado solo regule el presente. La naturaleza de la injusticia es que nosotros no siempre podremos verla en nuestro propio tiempo. Las generaciones que escribie- 
ron y ratificaron el Bill of Rights y la Enmienda Catorce no presumieron saber la extensión de la libertad en todas sus dimensiones, y así encomendaron a las futuras generaciones una carta protegiendo el derecho de todas las personas de gozar la libertad como conozcamos su significado. Cuando nuevas percepciones revelan discordancias entre las protecciones centrales de la Constitución y una inusual crítica legal, la libertad debe ser expresada”.

Pero como lo observó el juez Thomas en su voto disidente suscrito también por el juez Scalia, al analizar el concepto de "libertad" incorporado en la Enmienda Catorce, "desde bastante antes de 1787, libertad ha sido entendida como libertad en relación con la acción gubernamental, no como derecho a beneficios. Los redactores crearon nuestra Constitución para preservar ese entendimiento de libertad. Sin embargo, la mayoría invoca nuestra Constitución en el nombre de una 'libertad' que los Redactores no hubieran reconocido, en detrimento de la libertad que ellos buscaron proteger". Y continuó el juez Thomas en su voto disidente, expresando que sea que se defina "libertad" como derecho de locomoción o como libertad respecto de la acción del gobierno, en estos casos los peticionarios no pueden reclamar violación de su libertad, porque no han sido encarcelados o físicamente molestados por los Estados por participar en relaciones del mismo sexo, ni sus vidas han sido restringidas. Lo que ha sucedido es que los Estados se han negado a otorgarles beneficios gubernamentales, y su reclamo se basa en que tienen derecho a privilegios y beneficios que existen solo por la regulación gubernamental.

En orientación similar, como lo precisó el Chief Justice Roberts en su voto disidente, la Corte Suprema de Estados Unidos ha interpretado la Due Process Clause para incluir componentes

“[...] 'sustantivos' que protegen ciertos intereses de libertad contra privaciones por parte del Estado 'independientemente del proceso que se prevea'. Reno v. Flores, 507 U.S. 292, 302 (1993). La teoría es que algunas libertades están 'de tal manera enraizadas en las tradiciones y conciencia de nuestro pueblo que han de tener rango constitucional' y por tanto no pueden ser privadas sin una convincente justificación. Snyder v. Massachusetts, 291. Permitir que jueces federales no-electos seleccionen cuáles derechos no enumerados son los que deben tener rango de 'fundamentales' -y anular leyes estadales sobre la base de esa determinación- levanta preocupaciones obvias sobre el papel judicial. Nuestros precedentes en consecuencia han insistido que los jueces 'deben tener un gran cuidado' en identificar derechos fundamentales implícitos, y 'menos que la libertad protegida por la Due Process Clause sea sutilmente transformada en la preferencia política de los miembros de esta Corte' Washington v. Glucksberg, 521 U.S. 702, 720 (1997)”. 
En definitiva, como también lo precisó el Chief Justice Roberts en su voto disidente, para evitar el

"error salvado de convertir preferencias personales en mandatos constitucionales, nuestros modernos casos de debido proceso sustantivos insisten en la necesidad de 'auto-control judicial'. Collins v. Harker Heights, 503 U.S. 115, 125 (1992). Nuestros precedentes han requerido que un derecho fundamental implícito sea 'muy hondamente enraizado en la historia y tradición de esta Nación' y que 'implícito, en el concepto de libertad ordenada, es que ni la libertad ni la justicia existirían si fuese sacrificado'. Glucksberg, 521 U.S., at 720-721".

Concluyendo más adelante el Chief Justice Roberts en su voto disidente que "El propósito de insistir en que los derechos fundamentales implícitos tengan raíces en la historia y la tradición de nuestro pueblo es para asegurar que cuando jueces no electos anulan una ley sancionada democráticamente, lo hacen basados en algo más que sus propias creencias. La Corte hoy no solo repasó la completa historia y tradiciones de nuestro país, sino que la repudió activamente, prefiriendo vivir solo en los pesados días de aquí y ahora”.

Sobre el mismo tema de la utilización del término "libertad" utilizado en la Enmienda Catorce para fundar la sentencia el juez Alito en su joto disidente, expresó que

"La Constitución nada dice sobre el derecho de matrimonio del mismo sexo, pero la Corte sostiene que el término 'libertad' en la Cláusula del debido Proceso de la Enmienda Cuarta comprende este derecho. Nuestra Nación fue fundada sobre el principio de que toda persona tiene un inalienable derecho a la libertad, pero la libertad es un término de muchos significados. Para los liberales clásicos, puede incluir los derechos económicos ahora limitados por las regulaciones gubernamentales. Para los demócratas sociales, puede incluir el derecho a una variedad de beneficios gubernamentales. Para la mayoría de hoy, tiene un significado postmoderno particular. Para evitar que jueces no electos impusieran al pueblo americano su visión personal de la libertad, la Corte ha sostenido que la 'libertad' en la Cláusula de Debido Proceso debe ser entendida para proteger no solo esos derechos que están 'hondamente enraizados en la historia y tradición de esta Nación' Washington v. Glucksberg, 521 U.S. 701, 720-721 (1997). Y está fuera de toda disputa que el derecho al matrimonio del mismo sexo no está entre esos derechos. Véase United States v. Windsor, 570 U.S. (2013) (Alito, J., dissenting) (slip op., at 7). En efecto, 'En este país, ningún Estado ha permitido el matrimonio del mismo sexo hasta que la Corte Suprema de Justicia de Massachusetts sostuvo en 2003 que limitar el matrimonio a parejas de sexo opuesto violaba la Constitución del Estado. See Goodridge v. Department of Public Health, 440 Mass. 309, 798 N.E. 2d 941. 
$\mathrm{Ni}$ el derecho al matrimonio del mismo sexo está hondamente enraizado en las tradiciones de otras naciones. Ningún país permitió el matrimonio de parejas del mismo sexo hasta que los Países Bajos lo hizo en 2000. 'Lo que [esos que argumentan a favor de un derecho constitucional al matrimonio de mismo sexo] buscan, en consecuencia, no es la protección de un derecho hondamente enraizado sino el reconocimiento de un muy nuevo derecho, y buscan esta innovación no del órgano legislativo electo por el pueblo, sino de jueces no electos. Enfrentado a tal exigencia, los jueces tienen que tener tanto caución como humildad'. Id., at (slip op., at 7-8) (footnote omitted). Para la mayoría de hoy, no importa que el derecho al matrimonio del mismo sexo carezca de hondas raíces e incluso sea contrario a la larga tradición establecida. Los jueces en la mayoría reclaman la autoridad para conferir protección constitucional sobre tal derecho simplemente porque ellos creen que es fundamental".

\section{LA DIFICULTAD DE IDENTIFICAR LOS DERECHOS FUNDAMENTALES}

En todo caso, debe recordarse que la tarea de la Corte Suprema de Estados Unidos, particularmente en materia de identificar los derechos sociales como derechos fundamentales, no ha sido fácil, particularmente porque, como se ha dicho, la Constitución de 1787 y sus Enmiendas, solo contienen una escueta declaración constitucional de derechos 5 .

Una pieza esencial para el desarrollo de esa labor ha sido, sin embargo, la previsión de la Enmienda Novena de la Constitución, incorporada en 1791, conforme a la cual:

"La inclusión de ciertos derechos en la Constitución no se interpretará en el sentido de denegar o restringir otros derechos que se haya reservado el pueblo"6.

Esta importante cláusula abierta de la declaración de derechos, que confirma el carácter declarativo y no constitutivo de la enumeración constitucional, le ha permitido a la Corte Suprema identificar y proteger derechos constitucionales no declarados expresamente en el texto constitucional, considerados como inherentes a la persona humana. Cláusulas abiertas de este tipo, siguiendo el sentido de la

5 Véase Brewer-Carías, Allan R. "Sobre la justiciabilidad de los derechos sociales", en ponencia presentada el II Congreso Internacional sobre "Los Derechos Económicos y Sociales y su exigibilidad en el Estado Social y Democrático de Derecho", organizado por el Tribunal Constitucional de la República Dominicana, Santo Domingo, 26-29 de noviembre 2014.

6 Ninth Amendment (1791): "The enumeration in the Constitution, of certain rights, shall not be constructed to deny or disparage others retained by the people". 
Enmienda Novena, se incorporaron posteriormente en casi todas las constituciones de América Latina.

En todo caso, con este tipo de cláusulas, el listado de derechos constitucionales no se agota con los enumerados en el texto, así sean escuetos, sino que abarca todos aquellos inherentes a las personas y a la dignidad humana.

Esta fue la orientación de la argumentación de la Corte Suprema de Estados Unidos en el caso Griswold v. Connecticut decidido el 7 de junio de 1965 (381 U.S. 479; 85 S. Ct. 1678; 14 L. Ed. 2d 510; 1965), en el cual el juez Goldberg, al expresar la opinión de la Corte en relación con la declaración de inconstitucionalidad de una Ley del Estado de Connecticut sobre control de natalidad, por considerar que la misma violaba el derecho a la privacidad en el matrimonio, indicó:

"La Enmienda IX muestra la convicción de los autores de la Constitución de que existen derechos fundamentales que no están expresamente enumerados en las primeras ocho Enmiendas y la intención de que la lista de derechos incluidos allí no debe tenerse como exhaustiva [...].

Toda la estructura de la Constitución y de sus propósitos que claramente inspiran sus garantías específicas demuestra que los derechos a la privacidad marital y a casarse y levantar una familia son de un similar orden y magnitud que los derechos fundamentales específicamente protegidos. Aun cuando la Constitución no se refiere con muchas palabras respecto del derecho a la privacidad en el matrimonio, no puedo creer que la misma no ofrezca protección a esos derechos fundamentales. El hecho de que no haya una particular previsión en la Constitución que prohíba explícitamente al Estado el perturbar la relación tradicional de la familia -una relación tan vieja y fundamental como nuestra civilización entera-, con seguridad no implica que el Gobierno tenga el poder para ello. En cambio, como la Enmienda IX lo reconoce expresamente, hay derechos fundamentales personales como éste, que son protegidos frente restricciones por el Gobierno, aun cuando no esté mencionado específicamente en la Constitución”.

En otros casos, en los mismos Estados Unidos, otros derechos no expresamente regulados en la Constitución, como por ejemplo el derecho a la educación, sin embargo, no han encontrado una aproximación garantista como la indicada, ni ha sido considerado como un derecho fundamental, salvo por la vía de garantizar la igualdad y no discriminación en el disfrute del derecho.

En efecto, ese fue el meollo del caso Brown v. Board of Education of Topeka, 347 EE.UU. 483 (1954), con el cual puede decirse que en Estados Unidos comenzó el proceso de mutación de la Constitución en materia de derechos fundamentales, particularmente teniendo en cuenta que la Constitución de Es- 
tados Unidos de 1789 y las primeras diez enmiendas de 1791 no establecieron el principio de igualdad, y que la Enmienda Catorce (1868) solo estableció una cláusula de igualdad ante la ley, que hasta la década de 1950 tuvo un significado diferente.

Este proceso convirtió a la Corte, como lo han afirmado Laurence Claus y Richard S. Kay, en "el legislador más poderoso de la nación"7, habiendo utilizado para tal fin viejos pero renovados medios de protección, particularmente las injunctions de equidad para garantizar la protección de derechos en uno de los desarrollos más notables en el derecho constitucional contemporáneo, que ha producido cambios que solo años antes hubiera sido imposible imaginar. Esos medios judiciales de protección se comenzaron a utilizar ampliamente, precisamente en el caso Brown v. Board of Education of Topeka, en el cual la Corte Suprema sostuvo que la segregación racial en la educación pública era una negación de la "protección igual ante las leyes", y que en virtud de la Enmienda $\mathrm{XIV}$, ningún Estado, dentro de su jurisdicción, podría negarla a persona alguna. Para adoptar su decisión, la Corte tuvo que responder a varias interrogantes que se formuló para comprobar si la segregación era inconstitucional, como por ejemplo, si la orden judicial que debía emitir debía ordenar que los niños afroamericanos "fueran inmediatamente admitidos en las escuelas de su propia elección; o si el juez, en el ejercicio de sus poderes para imponer la igualdad, debía "permitir un ajuste gradual efectivo" para lograr sistemas unitarios ${ }^{8}$. Con el tiempo, dichas aproximaciones llevaron a la Corte Suprema, en mayo de 1954, a declarar la segregación racial como incompatible con la Enmienda XIV, dictando en mayo de 1955 la sentencia definitiva del caso, dos años y medio después de haber oído los alegatos iniciales?.

El resultado del proceso fue un cambio radical en relación con el tema de la discriminación en el sistema educativo, lo que a la vez fue básicamente un cambio en el propio significado de la Enmienda XIV, con respecto a lo cual el Chief Justice Warren de la Corte Suprema argumentó en el caso que

\footnotetext{
7 Véase Claus, Laurence y S. KaY, Richard, "Constitutional Courts as Positive Legislators in the United States", en Brewer-Carías, Allan R., Constitutional Courts as Positive legislators, Cambridge University Press, New York, 2011, pp. 815 y ss. Argumentan estos autores que eventualmente "la ley de la libertad y de la igualdad en los Estados Unidos es ahora, en gran medida, y en última instancia, creada y formada por el Tribunal Supremo", en Idem.

8 Brown v. Bd. of Educ., 345 U.S. 972, 972 (1953). Véase en Claus, Laurence y S. KaY, Richard, loc. cit. Idem.

9 Idem.
} 
"Al abordar este problema no podemos retroceder a 1868 cuando se adoptó la Enmienda, o incluso a 1896, cuando el caso Plessy v. Ferguson fue escrito. Debemos tener en cuenta la educación pública a la luz de su pleno desarrollo y su actual lugar en la vida estadounidense en toda la Nación. Solo de esta manera se puede determinar si la segregación en las escuelas públicas priva a estos demandantes de igualdad ante las leyes".

Esta afirmación llevó al propio Warren a concluir entonces que

"[...] en el ámbito de la educación pública la doctrina de 'separados pero iguales' no tiene lugar. Instalaciones educativas separadas son inherentemente desiguales. Por lo tanto, sostenemos que los demandantes, y otros en situación similar a partir de quienes se han interpuesto las acciones, son por razón de la segregación por la cual interpusieron el reclamo, privados de la igualdad ante las leyes garantizadas por la Enmienda Decimocuarta"10.

Pero en contraste con la protección al sistema educativo basada en la aplicación del principio y derecho a la igualdad y no discriminación que resultó del caso Brown v. Board of Education of Topeka, el derecho a la educación en sí mismo, como antes se dijo, no ha sido considerado en Estados Unidos como un derecho fundamental. Por ejemplo, en el caso San Antonio Independent School District et al. v. Rodríguez et al., de 1973, decidió que la educación, si bien "es uno de los más importantes servicios prestados por el Estado" (como se declaró en Brown v. Board of Education), no está dentro de la limitada categoría de derechos reconocida por esta Corte como garantizada por la Constitución". Con base en ello, la Corte Suprema negó a dicho derecho la cualidad de "derecho fundamental", insistiendo que "la educación, no obstante su indiscutida importancia, no es un derecho al que se reconoce, explícita o implícitamente, protección por la Constitución"11.

$\mathrm{Al}$ resolver el caso, la Corte Suprema se refirió a otra decisión anterior emitida en el caso Dandridge v. Williams, 397 U.S. 471 (1970), donde, tratando otras materias de asistencia social pública, sentenció:

"No es terreno de esta Corte el crear derechos constitucionales sustanciales a título de garantizar la igualdad de las leyes. De allí que la clave para descubrir si la educación es 'fundamental' no se encontrará en comparaciones sobre la significación social relativa de la educación, con la subsistencia o la vivienda. Ni tampoco se encontrará

10 Idem.

11411 U.S. 1; 93 S. Ct. 1278; 36 L. Ed. 2d 16; (1973), de 21 de marzo de 1973. En idem. 
al sopesar si la educación es tan importante como el derecho a movilizarse. Más bien, la respuesta yace en determinar si existe un derecho a la educación, explícita o implícitamente, garantizado por la Constitución”"12.

En apoyo del antes mencionado caso San Antonio Independent School District et al. v. Rodríguez et al., la Corte también se refirió a otro caso-Lindsay v. Normet, 405 U.S. 56 (1972) - dictado solo un año antes y en el cual reiteró que "la importancia social no es el determinante crítico para sujetar la legislación estadal a examen estricto", negando rango constitucional al derecho a tener una vivienda, disponiendo que sin denigrar de "la importancia de una vivienda decente, segura e higiénica", el hecho es que "la Constitución no dispone de medios judiciales para cada anomalía social o económica", siendo la materia de atribución legislativa y no judicial ${ }^{13}$.

Por consiguiente, el elemento clave para que los derechos humanos sean materia de protección constitucional -también en Estados Unidos- es el rango o reconocimiento constitucional que tengan como derechos, independientemente de la posibilidad que sean además regulados por las leyes.

\section{SObRE El DERECHO A CASARSE COMO DERECHO FUNDAMENTAL,}

EL DERECHO A ESCOGER PAREJA Y SU RELACIÓN CON LA PROTECCIÓN DE LA FAMILIA

Con todos estos antecedentes, para decidir la cuestión planteada sobre el derecho de los peticionarios al reconocimiento del derecho al matrimonio de las parejas del mismo sexo, la Corte Suprema para desentrañarlo no acudió a la Enmienda Novena, como en los casos antes mencionados, sino a la Enmienda Catorce, para lo cual comenzó por reconocer que desde mucho tiempo atrás había sostenido que el derecho a casarse está protegido por la Constitución, citando muchos casos judiciales. Entre los casos citados, se refirió al caso Loving v. Virginia, 388 U.S. 1, 12 (1967), mediante el cual la Corte invalidó prohibiciones de matrimonios interraciales, sosteniendo unánimemente que el matrimonio es "uno de los derechos personales vitales esenciales para el logro ordenado de la felicidad de los hombres libres".

La Corte precisó, sin embargo, que no podía negarse que todos los casos citados en su sentencia describiendo el derecho a casarse se referían a relaciones entre parejas de sexo opuesto, pues como muchas instituciones "hizo asunciones definidas en el mundo y en el tiempo de los cuales es parte”. Y además, en la sentencia del

12 En idem.

13 En idem. 
caso Baker v. Nelson, 409 U.S. 810, de 1972, al referirse a la competencia de los Estados, la Corte afirmó que la exclusión del matrimonio de parejas del mismo sexo no planteaba una cuestión federal sustantiva.

En todo caso, luego de analizar todos los precedentes jurisprudenciales, la Corte concluyó que ello la compelía "a la conclusión de que las parejas del mismo sexo podían ejercer su derecho a casarse", ya que "los cuatro principios y tradiciones que serían discutidos demuestran que las razones por las que el matrimonio es fundamental conforme a la Constitución se aplican con igual fuerza a las parejas del mismo sexo".

Esos cuatro principios que la Corte analizó en su sentencia son: primero, el derecho a escoger pareja; segundo, el carácter de derecho fundamental del matrimonio; tercero, su vinculación con otros derechos de la familia, y cuarto, el derecho al matrimonio de parejas del mismo sexo como parte del derecho a casarse.

La primera premisa que la Corte analizó de sus precedentes fue el derecho a escoger pareja, que se considera como un derecho fundamental que no puede ser restringido por el Estado. Sobre el mismo, en síntesis la sentencia reconoció:

"el derecho personal a la escogencia en relación con el matrimonio como derecho inherente en el concepto de autonomía individual. Fue esa conexión permanente entre matrimonio y la libertad por la que [la sentencia] Loving invalidó la prohibición de matrimonio interracial conforme a la Due Process Clause. See 388 U.S., at 12. [...] Como las escogencias relativas a la contracepción, las relaciones familiares, la procreación, y la crianza de los hijos, todos los cuales están protegidos por la Constitución, las decisiones concernientes al matrimonio están entre las más íntimas que un individuo puede tomar. [...] Efectivamente, la Corte ha notado que sería contradictorio 'reconocer el derecho a la privacidad en relación con materias de la vida familiar y no respecto de la decisión de entrar en la relación que es la fundación de la familia en nuestra sociedad' Zablocki, supra, at 386".

La naturaleza del matrimonio es que, a través de su promesa duradera, dos personas juntas pueden encontrar otras libertades, como las de expresión, intimidad y espiritualidad. Esto es cierto para todas las personas, sea cual fuere su orientación sexual. See Windsor, 570 U.S., at".

El segundo principio que destacó la Corte de su jurisprudencia es que el derecho a casarse es fundamental porque soporta la unión de dos personas como ninguna otra en su importancia de dedicación individual. Este punto, dijo la Corte, fue central en Griswold v. Connecticut, en la cual se sostuvo que la Constitución protege el derecho de las parejas casadas al uso de contracepti- 
vos (381 U.S., at 485), sugiriendo que el matrimonio es un derecho "tan viejo como el Bill of Rights".

Pero como lo observó el Chief Justice Roberts en su voto salvado, lo cierto es que la competencia para regular este derecho a casarse, conforme al sistema federal, es de los Estados, de manera que

"el derecho fundamental a casarse no incluye el derecho a hacer que un Estado cambie su definición del matrimonio. Y la decisión del Estado de mantener el significado del matrimonio que ha persistido en toda cultura a través de la historia de la humanidad difícilmente puede ser llamada irracional. En breve, nuestra Constitución no sanciona ninguna teoría del matrimonio. El pueblo de un Estado es libre de extender el matrimonio para incluir parejas del mismo sexo, o para retener la definición histórica. Hoy, sin embargo, la Corte adopta el extraordinario paso de ordenarle a cada Estado que licencie y reconozca el matrimonio del mismo sexo".

De lo anterior quedará pendiente, como lo observó el mismo Roberts, determinar "si los Estados podrán retener la definición del matrimonio 'como unión entre dos personas'. Cf. Brown v. Buhman, 947 F. Supp. 2d 1170 (Utah 2013), appeal pending, No 14-4117 (CA10)". "[...] Aun cuando la mayoría insertó erráticamente el adjetivo 'dos' en varias partes, no dio razón alguna sobre el porqué del elemento dos personas debe ser preservado en la esencia de la definición del matrimonio, al tiempo que el elemento hombre y mujer, no. En efecto, desde el punto de vista de la historia y tradición, un salto del matrimonio de sexos opuestos al matrimonio del mismo sexo, es mucho más grande que de una unión de dos personas a uniones plurales, las cuales tienen hondas raíces en algunas culturas alrededor del mundo"; destacando cómo "el razonamiento de la mayoría se podría aplicar con igual fuerza para reclamar un derecho fundamental al matrimonio plural".

La tercera base para proteger el derecho a casarse, de acuerdo con el razonamiento de la Corte, es la salvaguarda de los hijos y de la familia, de lo que deriva sentido con los derechos relacionados de crianza, procreación y educación, considerando además que el matrimonio permite la importante permanencia y estabilidad para los mejores intereses de los hijos, agregando: "Como todas las partes coinciden, muchas parejas del mismo sexo dan hogar afectuoso y cultivado hogar a sus hijos, sean biológicos o adoptados. Y cientos de miles de hijos están siendo en el presente levantados por dichas parejas". De allí concluyó la Corte, en consecuencia, que "excluir a las parejas del mismo sexo del matrimonio choca con la premisa central del derecho a casarse", y que "sin el reconocimiento, estabilidad y predictibilidad que ofrece el matrimonio, sus 
hijos sufren el estigma de saber que sus familias son en cierta forma menos", siendo en todo caso "el derecho a casarse menos significativo para esos que no quieren o no pueden tener hijos".

\section{LA LIBERTAD Y EL RECONOCIMIENTO}

DEL DERECHO DE LAS PAREJAS DEL MISMO SEXO A CASARSE

De las tres premisas anteriores, al reconocer la Corte la importancia del matrimonio en la historia y sociedad norteamericana, concluyó afirmando que por la misma razón "que las parejas prometen apoyarse mutuamente, igualmente la sociedad acepta apoyar las parejas, ofreciéndoles el reconocimiento simbólico y los beneficios materiales para proteger y sostener su unión"; enumerando entre la lista de derechos, beneficios y responsabilidades gubernamentales relativos al estatus marital, la propiedad, el derecho de herencia y propiedad, la sucesión, los privilegios de los esposos en materia de pruebas, el acceso a hospitales, las decisiones adoptadas por las autoridades médicas, los derechos de adopción, los derechos y beneficios de los sobrevivientes, certificados de nacimiento y de defunción, las reglas de ética profesional, las restricciones de financiamiento de campañas, los beneficios de compensación laboral, seguro de salud y reglas de custodia, apoyo y visita de los hijos.

Sobre este principio, concluyó la Corte que "no hay diferencia entre el mismo sexo o sexos opuestos", en cambio, mediante su exclusión de esta institución a las parejas de un mismo sexo se les niega la constelación de beneficios que los Estados vinculan al matrimonio", y que "la limitación del matrimonio solo a las parejas de sexos opuestos, si bien pudo haber sido vista como natural y justa", ahora "es manifiesta su inconsistencia con el significado central del derecho a casarse como derecho fundamental". Y así, decidió la Corte: "Con ese conocimiento tiene que venir el reconocimiento que las leyes que excluyen a las parejas del mismo sexo del derecho al matrimonio imponen un estigma y una injuria del tipo que está prohibido en nuestra Carta básica”.

Los demandados, sin embargo, argumentaron que los peticionarios en definitiva no buscaban el ejercicio del derecho a casarse sino, más bien, un inexistente "derecho al matrimonio del mismo sexo", ante lo cual la Corte, al repasar los antecedentes, decidió que en el caso Loving no se demandó sobre "un derecho al matrimonio interracial"; que en Turner no se demandó el "derecho de los prisioneros de casarse", y que en Zablocki no se demandó acerca de un "derecho de los padres con deberes de apoyo no pagados a sus hijos, de casarse". Al contrario, observó la Corte que en cada caso "se peticionó sobre el derecho de casarse en su 
sentido comprensivo, preguntando si había suficiente justificación para excluir las clases relevantes de derecho". Y según la Corte,

"ese principio se aplica aquí. Si los derechos fueran definidos por quien los ejerció en el pasado, entonces prácticas usuales pueden servir como sus propias justificaciones continuadas y nuevos grupos no podrían invocar derechos otrora negados. Esta Corte ha rechazado esa aproximación, tanto respecto del derecho a casarse como de los derechos de los homosexuales y lesbianas. Véase Loving 388 U.S., at 12; Lawrence, 539 U.S., at 566-567. El derecho a casarse es fundamental como tema de historia y tradición, pero los derechos no solo provienen de fuentes antiguas. Los mismos surgen, también, de un entendimiento mejor informado sobre cómo los imperativos constitucionales definen la libertad que permanece urgente en nuestra propia era. Bajo la Constitución, las parejas del mismo sexo buscan en el matrimonio el mismo tratamiento legal que las parejas de sexos opuestos, y negarles dicho derecho sería ridiculizar sus elecciones y disminuir su personalidad".

De todo lo anterior, la Corte concluyó considerando que "el derecho a casarse de las parejas del mismo sexo que es parte de la libertad prometida en la Enmienda Catorce, también deriva de la garantía de dicha Enmienda sobre protección igual por las leyes con la cual la anterior está profundamente conectada", llegando a la conclusión que

"el derecho a casarse es un derecho fundamental inherente a la libertad de las personas, y bajo las Cláusulas del Debido Proceso y de Igual Protección de la Enmienda Catorce las parejas del mismo sexo no puedes ser privadas del derecho fundamental de casarse. La Corte ahora sostiene que las parejas del mismo sexo pueden ejercer el derecho fundamental de casarse. Esa libertad no se les puede negar más".

Y como consecuencia de esta declaración, la Corte decidió que el caso Baker v. Nelson "debe ser y ahora es revocado (overruled) y que las leyes estadales impugnadas por los peticionarios en estos casos, son ahora consideradas inválidas en cuanto a que excluyen a las parejas del mismo sexo del matrimonio civil en los mismos términos y condiciones de las parejas de sexo opuesto".

Cuando se lee la sentencia cuidadosamente, cuyo fundamento para llegar a esta conclusión fue solo el concepto de libertad y trato igual por la ley, pero sin utilizar ni una sola vez la palabra discriminación, uno entiende el porqué de la convicción expresada por el Chief Justice Roberts, al expresar en su voto disidente que

"la verdad es que la decisión de hoy se apoya en nada más que las propias convicciones de la mayoría, de que a las parejas del mismo sexo debe permitírseles casarse 
porque ellos así lo quieren, y que negarles ese derecho sería ridiculizar su elección y disminuir su personalidad".

\section{CRÍticas de loS PROPIOS JUECES AL ACTIVISMO JUDICIAL EN RELACIÓN CON LOS DERECHOS FUNDAMENTALES}

Los jueces que formaron la mayoría, en todo caso, estaban conscientes del significado de la sentencia que estaban dictando y de su incidencia sobre los principios del control de constitucionalidad de las leyes. Por ello, luego de decidir el fondo, argumentaron que, "Por supuesto, la Constitución establece que la democracia es el proceso apropiado para los cambios, pero siempre que ese proceso no reduzca los derechos fundamentales", agregando que a finales del pasado período, "la pluralidad de esta Corte reafirmó la importancia del principio democrático en Schuette v. BAMN, 572 U.S. (2014)", destacando "el derecho de los ciudadanos a debatir, de manera que puedan aprender y decidir, y entonces, a través del proceso político, actuar en concierto y tratar de configurar el curso de su propio tiempo". Id., at (slip op., at 15-16).

Y en efecto, es lo más frecuente que sea a través de la democracia que la libertad sea preservada y protegida en nuestras vidas. Pero como Schuette también dijo: “[...] la libertad asegurada por la Constitución consiste, en una de sus dimensiones esenciales, en el derecho del individuo a no ser lesionado por el ejercicio ilegal del poder gubernamental. Id., at (slip op., at 15). En consecuencia, cuando los derechos de las personas son violados, 'la Constitución requiere reparación por las Cortes', a pesar del valor más general del proceso decisorio democrático. Id., at (slip op., at 17). Esto es verdad incluso cuando la protección de derechos individuales afecte temas que sean de la mayor importancia y sensibilidad". Y todo eso dicho para concluir que

"La dinámica de nuestro sistema constitucional es que las necesidades individuales no esperan la acción legislativa antes de afirmar un derecho fundamental. Las cortes de la nación están abiertas para los individuos agraviados que vienen directamente ante ellas a reclamar su propia parte personal en nuestra carta básica. Un individuo puede invocar un derecho para su protección constitucional cuando él o ella ha sido lesionado, incluso si el público en general no está de acuerdo e incluso si el legislador se niega a actuar”.

Sin embargo, como lo destacó el Chief Justice Roberts en su voto disidente, al constatar que el matrimonio de parejas del mismo sexo había tenido aceptación en once Estados y el Distrito de Columbia, donde se habían aprobado leyes para permitirlo, que ello no correspondía ser hecho por la Corte, porque 
"esta Corte no es una legislatura. Sea que el matrimonio del mismo sexo sea una buena idea ello debería estar fuera de nuestra preocupación. Bajo la Constitución, los jueces tienen el poder de decir qué es la ley, no qué es lo que debe ser. El pueblo que ratificó la Constitución no autorizó a las cortes a ejercer ni la fuerza ni la voluntad sino solo juicio". The Federalist No 78, p. 465 (C. Rossiter ed. 1961) (A. Hamilton) (capitalization altered).

Y de allí, el Chief Justice Roberts en su voto disidente concluyó, afirmando que no tenía otra opción que disentir, y que

"para quienes creen en el gobierno de las leyes, no de los hombres, la aproximación mayoritaria es hondamente desmoralizadora. Quienes apoyan el matrimonio del mismo sexo han obtenido un éxito considerable persuadiendo a sus conciudadanos -a través del proceso democrático- que acogiera sus puntos de vista. Ello terminó hoy. Cinco abogados cerraron el debate y sancionaron su propia visión del matrimonio como materia de derecho constitucional. Robándole este tema al pueblo, producirá para muchos una nube sobre el matrimonio del mismo sexo, provocando un dramático cambio social mucho más difícil de aceptar".

La decisión de la mayoría es un acto de voluntad, no de juicio legal. El derecho que anuncia no tiene base en la Constitución ni en los precedentes de esta Corte. La mayoría expresamente renuncia a la 'cautela' judicial y omite incluso una pretendida humildad, basándose abiertamente en el deseo de rehacer la sociedad de acuerdo con su propia percepción en la 'naturaleza de la injusticia'. [...] Como resultado, la Corte invalida las leyes matrimoniales de más de la mitad de los Estados y ordena la transformación de una institución social que ha formado la base de la sociedad humana por milenios, desde los Kalahari Bushmen y el Han Chino, los Cartagineses y los Aztecas. ¿Quién creemos nosotros que somos? Puede ser tentador para los jueces confundir nuestras propias preferencias con los requerimientos de la ley. Pero como esta Corte ha sido recordada a través de la historia, la Constitución 'es hecha para personas de visiones fundamentalmente diferentes'. Lochner v. New York, 198 U.S. 45, 76 (1905) (Holmes, J., dissenting). En consecuencia, 'no le concierne a las cortes las percepciones o las políticas de la legislación'. Id., at 69 (Harlan, J., dissenting). La mayoría de hoy desprecia esta concepción controlada del rol judicial. Y toma para sí una cuestión que la Constitución deja al pueblo, en un momento cuando el pueblo está comprometido en vibrantes debates en tal cuestión. Y responde a tal cuestión basado no en principios neutrales de derecho constitucional, sino en su propia 'preciación de que es la libertad y qué debe ser"”.

Por lo anterior, el juez Scalia concluyó en su voto disidente, suscrito también por el juez Thomas, diciendo que "Un sistema de gobierno que hace del Pueblo un subordinado de un comité de nueve abogados no merece llamarse como una 
democracia", y el Chief Justice Roberts, en su voto disidente precisó: "Si yo fuera un legislador, yo podría ciertamente considerar esa visión como una materia de política social. Pero como juez, y como materia de derecho constitucional, encuentro insostenible la posición de la mayoría".

Por eso precisó que su voto disidente no se refería si a su juicio la institución del matrimonio debía ser cambiada e incluir a las parejas del mismo sexo, sino, en realidad, era sobre "nuestra república democrática" y sobre si "la decisión debe quedar en manos del pueblo actuando a través de sus representantes electos, o en manos de cinco abogados que tienen el encargo que los autoriza a resolver disputas legales de acuerdo con la ley", concluyendo que "la Constitución no deja dudas sobre la respuesta”. Por ello, concluyó su voto disidente, expresándoles a todos los que celebren la sentencia, que lo hagan por todo lo que ella implica en cuanto a lo logrado, a la oportunidad por nuevas expresiones de compromiso con una pareja, y a la disponibilidad de nuevos beneficios, "pero no celebren la Constitución" pues "no tiene nada que hacer con ello".

\section{APRECIACIÓN FINAL}

El tema decidido por la Corte Suprema de Estados Unidos, al declarar el derecho constitucional de las parejas del mismo sexo a casarse como derecho fundamental, en todo caso, se resolvió con base en los principios de libertad y de igualdad ante la ley expresados en la Enmienda Catorce, y quizá le faltó a la Corte recurrir también a la cláusula abierta de los derechos contenida en la Enmienda Novena de la Constitución. Con la decisión adoptada, en consecuencia, se equiparó en cuanto a su régimen legal, a las uniones de parejas del mismo sexo con el matrimonio entre un hombre y una mujer, garantizando igualdad en cuanto al tratamiento y beneficios gubernamentales que pudieran tener. Eso en definitiva fue lo que demandaron los peticionarios, como lo resumió la Corte, en el sentido de

"encontrar esa libertad en casarse con alguien de su mismo sexo y tener su matrimonio considerado como legal en los mismos términos y condiciones como el matrimonio entre personas de sexo opuesto".

Ello también podía haberse resuelto, en el sentido de la equiparación en cuanto a los términos y condiciones, sin necesidad de cambiar la definición de "matrimonio". Como por ejemplo lo resolvió el texto mismo de la Constitución de Venezuela respecto del matrimonio y de las uniones estables, cuando luego de regular el "matrimonio entre hombre y mujer", agregó que "las uniones estables 
de hecho entre un hombre y una mujer [...] producirán los mismos efectos que el matrimonio" (art. 77). Para ello no había que llamar "matrimonio" lo que no era, pero la igualdad en el tratamiento de los derechos sí se estableció. Lo mismo quizá debió haber ocurrido en materia de uniones de personas del mismo sexo. Con base en la cláusula de igual tratamiento bajo la ley, y de libertad entendida como el libre desenvolvimiento de la personalidad, se pudo haber extendido a las parejas del mismo sexo todos los beneficios legales y regulaciones gubernamentales relativos al matrimonio entre personas de sexo opuesto, sin necesidad de considerarlas ni calificarlas como "matrimonio", cambiando una institución ciertamente milenaria.

La igualdad de tratamiento legal entre el marimono entre hombre y mujer y el matrimonio entre parejas del mismo sexo también se estableció por ejemplo en España, mediante la ley No 13/2005 de 1 de julio de 2005, que reformó el artículo 44 del Código Civil, mediante el agregado, luego de la previsión del mismo que establece que "El hombre y la mujer tienen derecho a contraer matrimonio conforme a las disposiciones de este Código", de un párrafo que dispone que "El matrimonio tendrá los mismos requisitos y efectos cuando ambos contrayentes sean del mismo o de diferente sexo".

La equiparación en todo caso es básica, sobre todo porque a pesar de que se hable de "matrimonio" y con ello se busque abarcar bajo una misma denominación legal tanto al matrimonio entre un hombre y una mujer como a la unión de parejas del mismo sexo, sigue habiendo una diferencia sustancial e imposible de superar, y es que precisamente, en el primer caso, se trata de una relación entre un hombre y una mujer, quienes entre ellos pueden procrear, y en el segundo caso, es una relación entre personas del mismo sexo, quienes entre ellas no pueden procrear. Precisamente porque esta diferencia que deriva de la naturaleza de las cosas no puede dejar de existir, ni siquiera en caso de inseminación artificial y menos de transexualidad, la Corte Suprema de Estados Unidos en la sentencia que hemos comentado no utilizó en sus razonamientos, ni una sola vez, la palabra "discriminación".

Sobre el tema central de la posibilidad de procrear, sin embargo, lo único que dijo la Corte es que ello es solo uno de los muchos aspectos del derecho constitucional a casarse, reconociendo, por supuesto, que las parejas de un hombre y una mujer que no pueden o no quieren procrear hijos no podrían estar excluidas del derecho al matrimonio, ni las leyes de los Estados podrían condicionar el matrimonio de un hombre y de una mujer a la capacidad de procreación.

Pero el tema de la posibilidad y necesidad de procreación es importante destacarlo, porque ello es precisamente lo que distingue las características de la discusión pública sobre el tema del matrimonio de personas del mismo sexo 
en Estados Unidos de otros casos de restricción de derechos que sí entran en el marco de la discriminación, aunque se quiera poner todo en una misma cesta ${ }^{14}$, y que durante decenas de años han dominado la discusión pública en Estados Unidos. Ha sido el caso, por ejemplo, de temas que han sido resueltos por la Corte Suprema, como por ejemplo sobre la discriminación racial, la discriminación de los homosexuales o la discriminación de las mujeres, y que en la cultura norteamericana ha contribuido a superar otras discriminaciones culturales, como la que excluía la aspiración de católicos, afroamericanos o mujeres a ser electos como presidente de Estados Unidos, lo cual, por los hechos, ya se encuentra superado.

Por eso, el tema constitucional decidendum en la sentencia de la Corte Suprema aceptando el derecho a casarse en matrimonio a parejas del mismo sexo no fue el de discriminación, porque ninguna de las leyes de Estados declaradas inválidas en realidad discriminaba, por exclusión, la unión de personas del mismo sexo; simplemente no las regulaba porque se consideraba, en el concepto histórico y universal, que el matrimonio es solo posible entre un hombre y una mujer. La sentencia, por ello, para decidir y satisfacer la demanda de los peticionarios, de "encontrar esa libertad en casarse con alguien de su mismo sexo y tener un matrimonio considerado como legal en los mismos términos y condiciones como el matrimonio entre personas de sexo opuesto", se basó en los principios de libertad e igual trato ante la ley.

Para ello, por supuesto, la Corte Suprema le dio al concepto de "libertad", la concepción amplia que hoy tiene en el mundo contemporáneo, como derecho al libre desenvolvimiento de la personalidad, tal como se deduce de la sentencia, al expresar que, negarles a las parejas del mismo sexo que busquen en el matrimonio el mismo tratamiento legal que las parejas de sexos opuestos, significa "disminuir su personalidad".

De nuevo, quizá en constituciones redactadas en tiempos más modernos, el juez constitucional hubiese tenido una tarea más fácil para encontrar en el concepto de "libertad" la idea del derecho al "libre desenvolvimiento de la personalidad", como es el caso de la Constitución de Venezuela, en la cual desde 1961 se incorporó una norma con la cual se abre la declaración de derechos, que expresa que "Toda persona tiene derecho al libre desenvolvimiento de su personalidad, sin más limitaciones que las que derivan del derecho de los demás y del orden público y social” (art. 43 Constitución 1961; artículo 20 Constitución 1999).

14 Véase, por ejemplo, el reportaje de David Leonhardt y Alicia Parlapiano, "A March Toward Acceptance When Civil Rigts Is the Topic", The New York Times, New York, June 30, 2015, p. A\#. 
Con dicha norma, como se explicó en la Exposición de Motivos de la Constitución de 1961, se sustituyó "el enunciado tradicional de que todos pueden hacer lo que no perjudique a otro y nadie está obligado a hacer lo que la ley no ordene ni impedido de ejecutar lo que ella no prohíba", que es, precisamente, el enunciado tradicional de "libertad".

New York, 30 de junio de 2015. 